\title{
Is total femoral replacement for non-oncologic and oncologic indications a safe procedure in limb preservation surgery? A single center experience of 22 cases
}

Andreas Toepfer ${ }^{1 *}{ }^{*}$, Norbert Harrasser $^{1 \dagger}{ }^{\dagger}$, Isabel Petzschner ${ }^{2}$, Florian Pohlig ${ }^{1}$, Ulrich Lenze ${ }^{1}$, Ludger Gerdesmeyer ${ }^{3}$, Ruediger von Eisenhart-Rothe ${ }^{1}$, Heinrich Mühlhofer ${ }^{1}$ and Christian Suren ${ }^{1}$

\begin{abstract}
Background: Several surgical options for the reconstruction of massive bone defects have been described and include biologic methods with autografts and allografts, and the use of tumor endoprostheses (total femoral replacement, TFR). Several types of modular TFR are available, but nevertheless unpredictable outcomes and high complication rates have been described from most authors. The present study aims to compare results after TFR performed with modular total femur prosthesis MML (Fa. ESKA/Orthodynamics) in patients with and without malignant disease.

Methods: Retrospective chart review and functional investigation (Musculoskeletal Tumor Society (MSTS) score, Harris Hip Score (HHS), Oxford Knee Score (OKS), SF-12 Health Survey, and failure classification according to Henderson) of TFR cases from 1995 to 2011. Indications for TFR were malignant tumor resection from the femur ( $n=9$, Group A) or failure of a revision arthroplasty without history of malignant disease ( $n=13$, Group B).

Results: Thirty-six patients were treated during the study period, of whom 22 could be investigated clinically after a mean follow-up of 63 months. Overall failure rate for TFR was 59.1\%, leading to 38 surgical revisions. The most common failure mechanisms were Type I (soft tissue), followed by Type IV (infection) and Type III (mechanical failure). Mean MSTS score out of 30 was 13 (range 1-25), with significantly higher scores in Group A (mean 19, range 3-25) than Group B (mean 9, range 1-15).
\end{abstract}

Conclusion: TFR is an established procedure to restore femoral integrity. However, complication rates are considerably high, and depend mainly on the age at initial reconstruction.

Keywords: Total femoral replacement, Revision arthroplasty, Infection, Non-oncologic megaprosthesis

\section{Background}

Several surgical techniques for the reconstruction of extensive bone defects have been described and include biologic options, and the use of tumor endoprostheses [1]. Such endoprosthetic bone and joint replacements have developed from customized devices to modern

\footnotetext{
*Correspondence: Toepfer@tum.de

${ }^{\dagger}$ Andreas Toepfer and Norbert Harrasser contributed equally to this work and share first authorship

${ }^{1}$ Department of Orthopedics and Sports Orthopedics, Technical

University of Munich, 81547 Munich, Germany

Full list of author information is available at the end of the article
}

implants with a variety of modular options to replace massive bone defects [2]. At the level of the femur the replacement of the whole bone including the hip and knee joint is an extreme example for limb preservation surgery in modern tumor prosthetics. Total femoral replacement (TFR) is able to reconstruct femoral integrity and usually patients resume mobilization. It comes as little surprise that functional capacity of TFR is compromised compared to conventional hip or knee prostheses, but nevertheless its function is deemed superior to hip disarticulation. Even though several authors reported their results of TFR $[1,3-16]$, so far many questions are 
still on debate: It is still unclear, which patients are at risk to experience low functional outcome after this procedure. Hence, it is not well understood, whether complications after TFR depend on the indication for the surgery (e.g., failure of revision arthroplasty or tumor disease) or the age of the patients. Additionally, there have been few reports that compare functional outcomes after TFR for various indications $[3,5,7,17,18]$.

Therefore, the aim of the present study was to report the results in patients treated with modular total femur prosthesis MML from one orthopedic center. We asked the following questions: (1) Which patients experience a complication or a failure of TFR? (2) Do the complications vary with the indication for TFR (malignant disease vs. revision arthroplasty)? (3) What are the functional outcomes of TFR?

\section{Methods}

Approval of the respective institutional review boards was obtained before commencement of the study. We retrospectively reviewed our institution's database for patients with resection of the femur owing to malignant bone tumors or failed revision arthroplasties and defect restauration by TFR from January 1995 to January 2011. Reconstruction of bone defects was performed with a modular total femur prosthesis (MML, ESKA/ Orthodynamics, Luebeck, Germany; Fig. 1) comprising a monopolar femoral head component and a fully constrained total knee system. Our database research revealed 36 patients (36 implants) with TFR. Twelve were excluded (eight died from malignant disease, four sustained a hip disarticulation due to persistent periprosthetic infection). Of the 24 remaining patients, two were lost to follow-up within 6 months of surgery. Thus, a total of 22 patients were included in our study (Fig. 2). These patients were contacted by telephone, interviewed, and clinically assessed. Demographic data of the cohort are given in Table 1. Patients were subdivided into Groups $\mathrm{A}$ and $\mathrm{B}$ according to the indication for TFR: malignant musculoskeletal disease (Group A; $n=9$; mean age 47 $(36-82)$ years) or failed revision arthroplasty (Group B; $n=13$; mean age 73 (64-90) years). Surgical details, follow-up, complications, and functional scores for massive bone defect reconstruction [Musculoskeletal Tumor Society (MSTS) score] were recorded. Additionally, functional scores evaluating results after hip and knee surgeries [Harris Hip Score (HHS), Oxford Knee Score (OKS)], pain [visual analogue scale (VAS)], and overall health-related-quality of life (SF-12 Health Survey) were analyzed. At the latest follow-up of patients of Group A, eight (89\%) were continuously disease free, and one (11\%) was alive with disease (multiple metastases). Complications were analyzed according to the classification

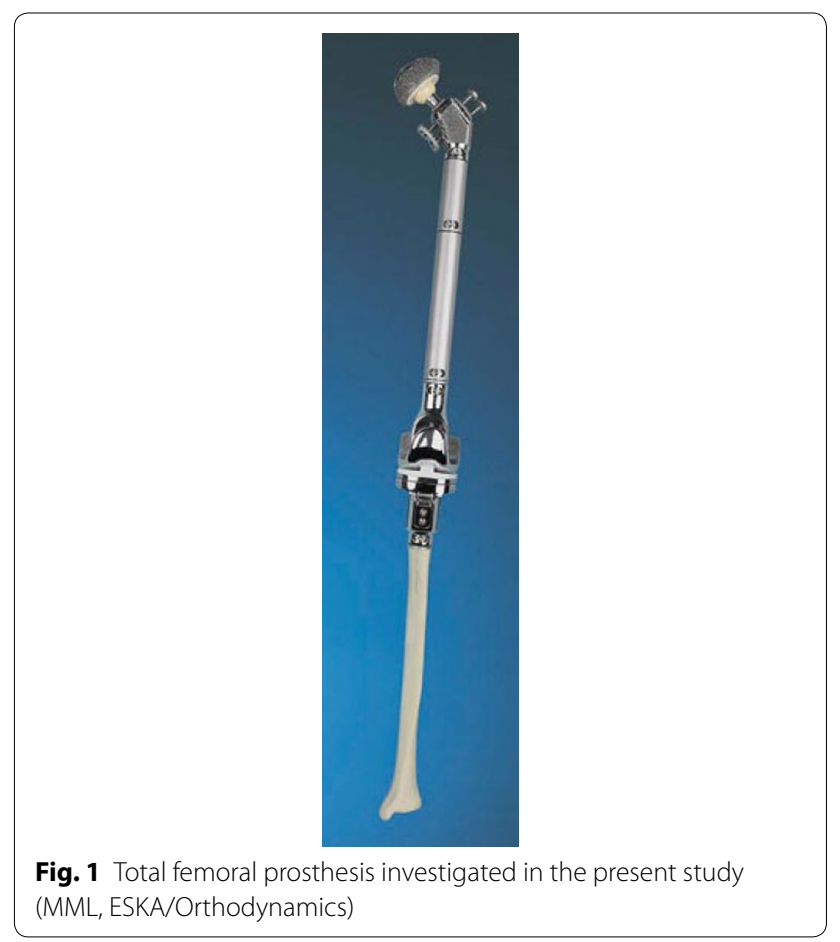

proposed by Henderson et al. [19]: Type I is soft tissue failure (e.g., instability of the prosthesis, tendon rupture or avulsion, aseptic wound dehiscence); Type II is aseptic loosening with clinical and radiographic signs of loosening; Type III is structural failure, including periprosthetic fracture or device failure or deficient osseous supporting structure; Type IV is periprosthetic infection requiring removal and subsequent reimplantation of the implant; Type V is tumor progression.

\section{Statistics}

Survivorship analysis was performed using the KaplanMeier survivorship method. All data are reported as the mean, range, and percentage, where applicable. Comparisons of patient-reported outcomes were performed using a $t$ test for unpaired samples. Statistical significance was set at $p<0.05$. Correlations between numerical data were done with linear regression analysis, and Pearson's correlation coefficient $(r)$ is reported. Statistical analysis was performed using SPSS 2.0 (IBM, Armonk, NY, USA).

\section{Results}

\section{Indication for TFR}

All patients in either group had reported of one or more surgical procedures (nail, primary hip and/or knee prosthesis or megaprosthesis) before implantation of TFR. Various indications for prosthetic reconstruction with TFR are given in Table 2. In Group A, 14 revision surgeries were observed in a total of four individuals, which 


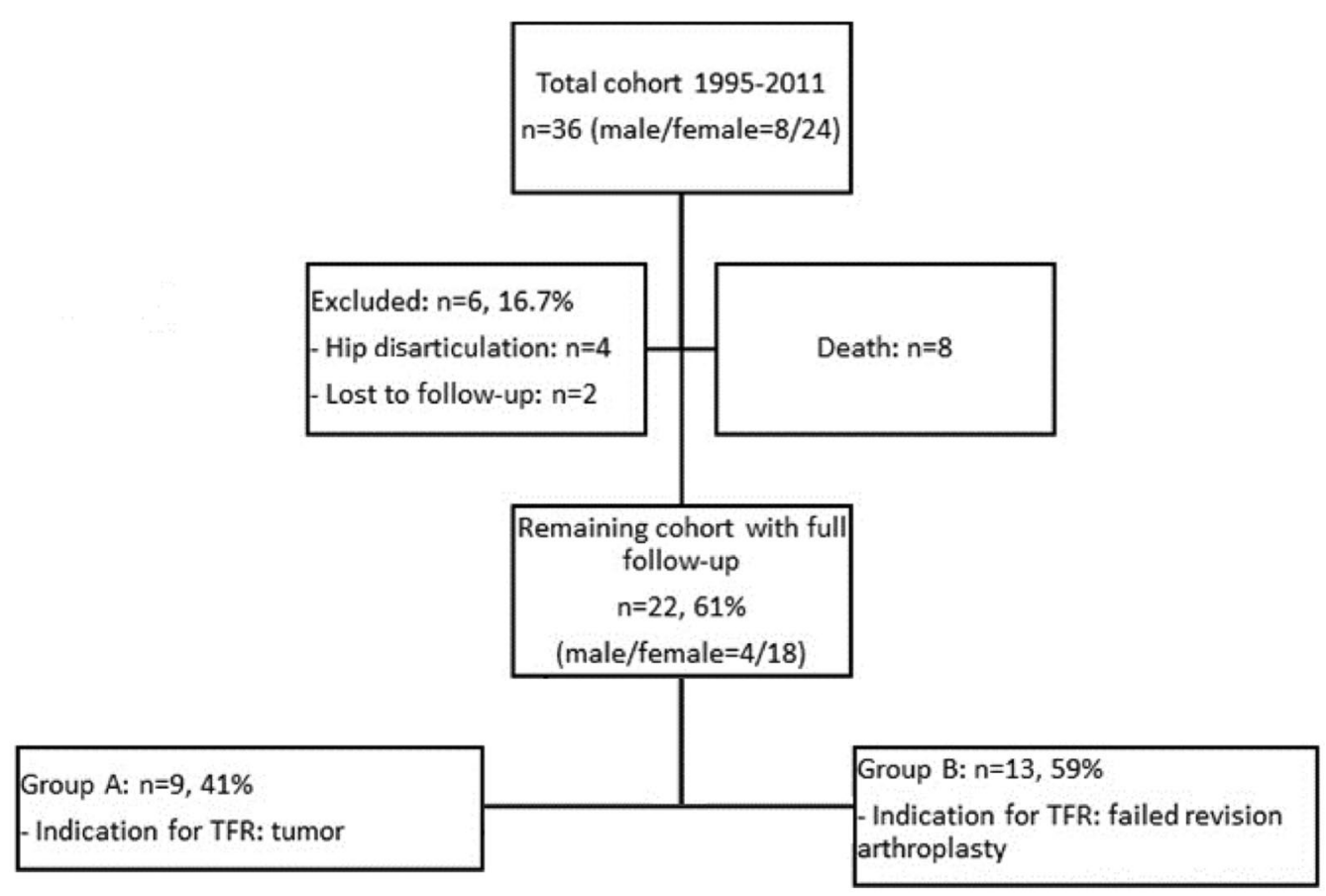

Fig. 2 Total cohort and patients included in the study groups

Table 1 TFR patient demographics

\begin{tabular}{|c|c|c|c|}
\hline Demographic & $\begin{array}{l}\text { All patients (average } \pm \text { standard devia- } \\
\text { tion) }\end{array}$ & Group A: oncologic patients & Group B: failed arthroplasty patients \\
\hline Age at reconstruction (years) & $66 \pm 20$ years (range $36-90)$ & $47 \pm 18$ years (range $36-82$ ) & $73 \pm 8$ (range 64-90) \\
\hline Sex (male/female) & $4 / 18$ & $3 / 6$ & $1 / 12$ \\
\hline Height (cm) & $164 \pm 9$ & $163 \pm 6$ & $165 \pm 7$ \\
\hline Weight (kg) & $77 \pm 10$ & $75 \pm 5$ & $78 \pm 11$ \\
\hline $\mathrm{BMI}\left(\mathrm{kg} / \mathrm{m}^{2}\right)$ & $28.8 \pm 4.4$ & $28 \pm 4$ & $29.1 \pm 6.1$ \\
\hline Mean follow-up (months) & $63 \pm 37$ months (range 13-152) & $59 \pm 48$ months (range 13-152) & $62 \pm 30$ months (range 22-110) \\
\hline Side of TFR (right/left) & $12 / 10$ & $6 / 3$ & $6 / 7$ \\
\hline
\end{tabular}

corresponds to 1.4 (median $=0$; range $0-7$ ) revisions per patient prior to TFR. All other patients were converted to TFR from subtotal (proximal (PFR) or distal (DFR) femoral replacement) during the first revision surgery. In Group B, five patients had received a modular megaprosthesis after multiple failed revision procedures in the past. Only two patients received their TFR as a result of the first revision surgery. Hence, 11 patients had a history of 33 revision surgeries prior to their TFR, resulting in 2.4 (median $=2$; range $0-8$ ) revisions per patient. The difference between both groups was not significant $(p=0.18)$.

\section{Complications}

The mean time from operation to the development of a complication (according to Henderson) was 13.4 (0-119) months, with a mean time to complication of $24(0-119)$ months for Group A and 6 (1-9) months for Group B. Time to complication varied according to failure mode: Type I presented at an average of $12(0-54)$ months after surgery, Type III at $44(40-48)$ months, and Type IV at 50 (4-119) months. Type II and V failure were not observed in any of the patients. Overall, there were 20 implantrelated complications in 14 patients (64\%) with all of these being Type I, III or IV failures (Table 3). Complications yielded to 38 revision surgeries and an overall failure rate for TFR of $59.1 \%$.

\section{Analysis of complication types}

Type I (soft tissue failure): recurrent hip dislocations were reported in five patients (two in Group A, three 


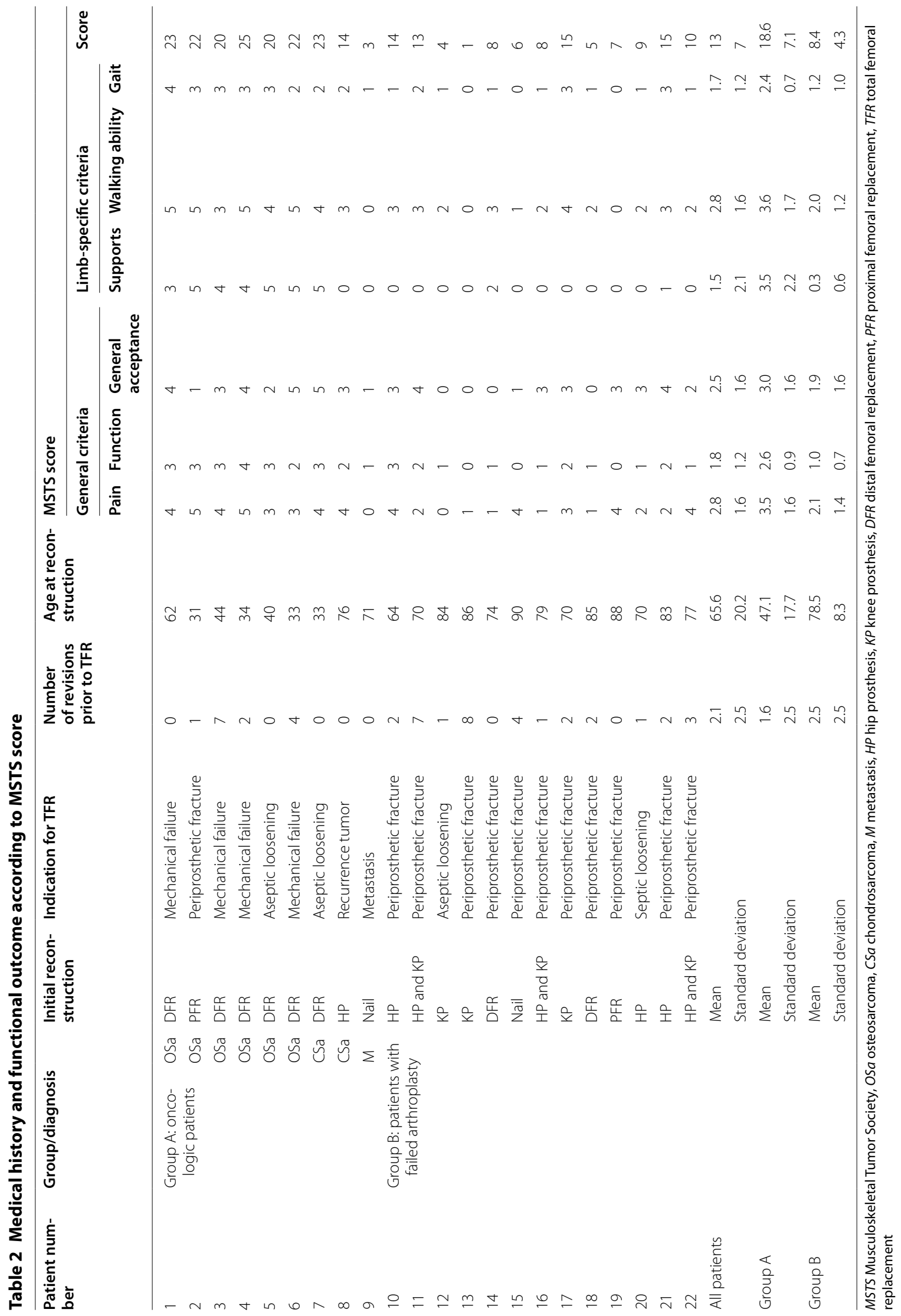


Table 3 Number of implant failures in the present series as classified according to Henderson et al. [13]

\begin{tabular}{llll}
\hline Type of failure & Group A $(\boldsymbol{n}=\mathbf{9})$ & Group B $(\boldsymbol{n}=\mathbf{1 3})$ & Total number of complications \\
\hline I (soft tissue failure) & 3/9 dislocations & $2 / 13$ dislocations & 5 \\
& 2/9 wound healing problems & $4 / 13$ wound healing problems & 6 \\
II (aseptic loosening) & $-1 / 9$ arthrofibrosis & $1 / 13$ arthrofibrosis & - \\
III (structural) & $-1 / 9$ breakage of bolt & - & 2 \\
IV (infection) & $1 / 9$ & $1 / 13$ breakage of bolt & 5 \\
V (tumor progression) & - & $4 / 13$ & - \\
Total & 8 & - & 20 \\
\hline
\end{tabular}

20 complications were found in 14 patients (some patients had multiple failures)

in Group B), all of whom were reduced without surgery and underwent conservative treatment. Two patients were treated surgically with three subsequent revision procedures (head replacement, inlay and head replacement, and cup replacement). Wound healing problems were reported in six patients (two in Group A, four in Group B) ending up in ten surgical interventions in five patients. Knee arthrofibrosis was present in one case in each group.

Type III (structural failure): a mechanical failure of the TFR was observed in one patient of either group. In both patients, a failure at the level of the knee system was observed. Both knee modules had to be replaced.

Type IV (deep infection): septic complications of the TFR were observed in five patients (one in Group A, four in Group B) with 21 revision interventions.

\section{Implant survival analysis}

Twenty-two patients were included in the survivorship analysis using Kaplan-Meier curves (Fig. 2). Implant failure (i.e., exchange of prosthetic modules due to implantrelated complications) was detected in $18.2 \%$ (four cases of 22) of all TFR at an average follow-up of 5 years after primary reconstruction. Another three implant failures occurred after the fifth year from implantation, raising the failure rate to $7 / 22(31.8 \%)$. Complications led to a partial or total exchange of the prosthesis after an average of 14 months from TFR. Uneventful implant survival was observed in only nine (40.9\%) of the 22 patients (Fig. 3 ).

\section{Clinical outcome}

Patients in the present study had a mean VAS value (Maximum: 10, Minimum: 0) of 5.7 preoperatively (Group A: 4.5; Group B: 5.8) and 3.4 after TFR (Group A: 1.9, Group B: 4). Difference was statistically significant between pre- and postoperative VAS values within each group ( $p=0.04)$, and between groups for pre- and postoperative values $(p=0.01)$.

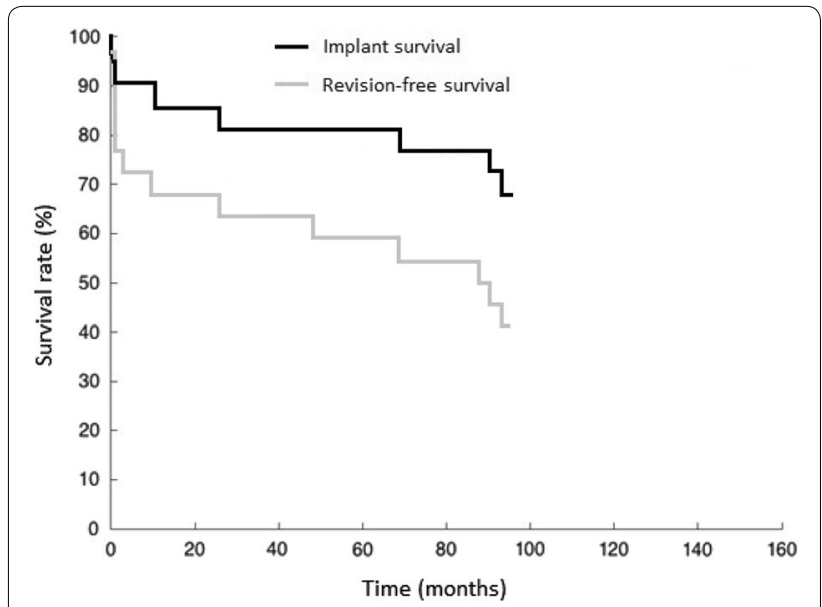

Fig. 3 Kaplan-Meier survival analysis. 5-year TFR implant survival $=81.8 \%$; 5 -year revision-free survival $=59 \%$

The mean MSTS score (out of 30) across both groups was 13 (43\%, range 1-25). Scores in Group A (19 (64\%), range $3-25)$ were significantly $(p=0.003)$ higher than in Group B (9 (30\%), range 1-15). Sub-score analyses revealed significant differences between the groups in function $(p=0.002)$, supports $(p=0.001)$, walking ability $(p=0.007)$, and gait $(p=0.005)$. Statistical analysis revealed a strong negative correlation between age and clinical outcome (MSTS) after surgery $(r=-0.86)$. On the other hand, only a weak negative correlation was found for number of revision surgeries prior TFR and clinical outcome (MSTS) after surgery $(r=-0.11)$.

Clinical outcome data computed by HHS and OKS, as well as results of SF-12 analysis are given in Table 4 .

\section{Discussion}

Reconstruction of massive bone defects of the femur after oncologic resection or failed revision arthroplasty represents a challenge for orthopedic surgeons. Here, we analyzed 36 TFRs, and reviewed the clinical and 
Table 4 Functional outcome results of both groups

\begin{tabular}{|c|c|c|c|}
\hline Items & $\begin{array}{l}\text { Group A [value, } \\
\text { (range)] }\end{array}$ & $\begin{array}{l}\text { Group B [value, } \\
\text { (range)] }\end{array}$ & $p$ value \\
\hline \multicolumn{4}{|l|}{$\mathrm{HHS}$} \\
\hline Mean score & $69.7(12-88)$ & $35.4(15-57)$ & 0.007 \\
\hline Pain & $31.6(0-44)$ & $17.7(10-40)$ & 0.002 \\
\hline Function & $21(0-30)$ & $6.2(0-14)$ & 0.001 \\
\hline Activity & $10(5-12)$ & $5.2(0-10)$ & 0.002 \\
\hline Contractures & $3.9(3-4)$ & $3.7(3-4)$ & 0.6 \\
\hline Motion & $3.2(2-5)$ & $2.7(2-4)$ & 0.2 \\
\hline \multicolumn{4}{|l|}{ OKS } \\
\hline Mean score & $26.2(5-39)$ & $15.3(4-26)$ & 0.03 \\
\hline \multicolumn{4}{|l|}{ SF-12 } \\
\hline $\begin{array}{l}\text { Physical subdo- } \\
\text { main }\end{array}$ & $38.3(21.9-50.1)$ & $28.1(21.3-35.6)$ & 0.02 \\
\hline $\begin{array}{l}\text { Mental subdo- } \\
\text { main }\end{array}$ & $52.5(10.5-62.7)$ & $48.5(27.3-62.9)$ & 0.2 \\
\hline
\end{tabular}

functional outcomes of 22, in patients with a history of malignant diseases (Group A) or failed revision arthroplasties (Group B). To the best of our knowledge, there is no published case series using a standardized failuremode classification of TFRs performed with the MML system (Fa. ESKA/Orthodynamics).

One of the main findings of the present study is the significant difference in clinical outcome between the groups (Table 2). Linear regression analysis with the potentially most influential factors for clinical outcome (age, surgeries prior TFR) showed a strong negative correlation only for age. This finding partially agrees with previous studies showing significant differences between indication for TFR, age at TFR and number of revisions prior to TFR $[19,20]$. The oncological cohort in the present study showed high rates of disease-free survival. Six patients with osteosarcoma (mean follow-up: 7.7 years) and two patients with chondrosarcoma (mean follow-up: 1.8 years) were continuously disease free. Comparing the drop-outs $(n=8$; all patients died of progressive tumor disease) of the initial cohort of 36 patients and patients of Group A (eight still alive without recurrence, one with metastatic disease) we found that the local extent of the primary tumor and the presence of metastases were negatively correlated with survival. In all drop-outs a local extend of the tumor of more than half the length of the femur was present, while in all patients of group A the initial tumor was less than half of the length of the femur. All patients with initial metastatic disease and primary reconstruction with TFR had died at a mean of 9 month after surgery. Of the eight drop-outs, one died of an osteosarcoma (G2), one of a chondrosarcoma (G3), one of a pleomorphic sarcoma (G3) and five of metastases due to lung/renal cell/rectum carcinoma. All patients of group A except for one (patient 9: renal cell carcinoma) had suffered from a sarcoma and all were graded three. Hence, grading of the sarcomas did not influence survival in our series. Therefore, it is difficult to provide universal surgical guidelines for decision-making between reconstruction with TFR or hip disarticulation in these patients. It seems that the survival of patients with extensive tumorous disease cannot be improved with either surgical method.

We found an overall non-oncologic complication rate of $59.1 \%$ in our patients who underwent TFR (Fig. 3). It should be noted that none of the patients included in the present study $(n=22)$ had a primary defect reconstruction with TFR. In fact, 47 revision surgeries were performed in the study population prior to TFR. Only seven out of 22 patients received their TFR within the first revision of their megaprosthesis or intramedullary nail. Statistical analysis revealed only a weak negative correlation for number of revision surgeries prior TFR and clinical outcome after surgery. This is important because outcome after TFR has not been correlated with prior revision surgeries so far.

Analysis of failures after TFR revealed some differences between the groups. Type I failure (soft tissue failure) was detected in 13 cases necessitating 15 surgical revisions. Wound healing problems (six patients, 27\%) and hip dislocations (five patients, 23\%) were the most common complications among Type I failures. Incidences of these complications are reported to vary between 0 and $45 \%[3,6,8,9,11]$. From large series with primary hip arthroplasty, it is known that $75 \%$ of dislocations occur within the first 2 months of implantation [21]. In our study, this was observed in $67 \%$ of dislocations. To prevent hip dislocation in cases of residual trochanteric bone or viable tendinous abductor structures, we preferred direct attachment to the endoprosthetic implant using non-resorbable sutures. Alternatively, the ligament augmentation reconstruction system $\left(\right.$ LARS $\left.^{\circledR}\right)$ may be a helpful tool for more stable soft tissue repair in cases of extensive loss [12]. Additionally, promising results regarding hip stability can be obtained if tripolar cups are used [2, 3, 22].

In our series, no Type II failure (aseptic loosening) was found, confirming previous reports of a low incidence of this failure type in TFR $[6,9]$. In cases using megaprostheses, this type of failure was reported at a rate of 2.4$15.4 \%$ for cemented [23-26] and $0-8 \%$ for cementless implants [10, 27-29]. Unlike PFR or DFR, TFR implantation does not rely on diaphyseal stem fixation but uses the common techniques of total hip arthroplasty and 
(fully constrained) total knee arthroplasty with a standard acetabular cup and tibial metaphyseal stem fixation. This and the lower activity level of patients from the present study might explain the results for aseptic loosening with TFR compared with PFR and DFR.

Structural failure (Type III) was observed in two patients in our series, namely a prosthetic breakage at the level of the hinged knee joint. In both cases, the affected prosthetic parts were replaced and no further material failure was observed. In the literature, the incidence of prosthetic component breakage in megaprostheses is 0-7.7\%, with lower incidences in TFR than in PFR/DFR. Again, this might be attributed to the absence of diaphyseal stems in TFR, which are known weak spots in modular megaprostheses [30]. Other authors conclude that the lower mobility and activity in this population is a reason for lower rates of structural failure $[10,23,25,26,28$, 29]. In our experience, bolt breakage at the level of the hinged knee module occurred mostly in the first-generation design of the MML prosthesis in patients with DFR, where the whole load is carried by the central axis bolt. This bolt was strengthened in second-generation prostheses, which have been used since the late 1990s [30].

Type IV failure (deep infection) was observed in five patients (22\%) in our series. Note that another four cases with hip disarticulation due to persistent periprosthetic TFR infection were excluded from the initial cohort of 36 patients. Hence, a total infection rate of $25 \%$ (nine out of 36) was observed in our study. These data are comparable to findings described in the recent literature $(0-20 \%$ in TFR) $[3,6,8,9,11,22]$. Permanent eradication of infection was achieved in all cases in our cohort with a total of 21 revisions.

Type V (implant-independent) failure was never observed in our cohort. Other authors described rates between 5 and $20 \%[3,8,9,11]$.

Analyzing the occurrence of implant-related complications in the course of time, we found some specific differences between the various failure modes according to Henderson: Type I failures (soft tissue) occurred after an average of 12 months after surgery, and included mainly instability or aseptic wound dehiscence. On the other hand, Type III (structural failure) and IV (periprosthetic infection) failures occurred after an average of 44 and 50 months, respectively. The differences between these short-term and mid-/long-term complications is not surprising, taking into account that Type I complications are more related to the surgical procedure itself and Type III complications to the implant. However, these differences have so far not been described in the context of TFR. The finding that Type IV complications occurred rather late in the present study is only partially supported by data in the literature, where early and late occurrence of periprosthetic infections of TFR have been described [5, $7,14,22]$.

Functional outcome measurement with respect to the MSTS score, as the only established score for evaluation of massive bone reconstructions, revealed an average value of $13(43 \%)$ in the present study, inferior to other studies, which reported scores of 17-24 (59-80\%) (Table 5). However, consideration of individual cases from both groups is necessary for adequate interpretation: one patient in Group A was in a palliative condition and unable to sit or stand owing to his disease at latest follow-up and two patients in Group B suffered from advanced dementia. Additionally, there was a significant difference of 26 years in the mean ages of the two groups. This is the most influencing factor for MSTS score differences between the groups as shown in linear regression analysis. HHS is a well-established hip score and has so far only been used by Berend et al. to evaluate hip function in TFR [4]. In their series, an average value of 70 was detected. In the present study, an overall score of 49 was identified, also with a significant difference between the groups (Table 4). Evaluation of TFR cannot be compared with results from primary or "conventional" revision total hip arthroplasty. OKS has so far not been used to evaluate TFR. In the present study, a rather low average value (Table 4) was observed, but again there was a significant difference between the groups. As with HHS, OKS does not seem to be an appropriate tool with which to evaluate functional outcome after TFR.

In summary, VAS and functional outcome measures revealed a significant reduction in pain after TFR compared with preoperative values. Function with mobility was reduced in both groups, but significantly better results were observed in patients from Group A. This finding was supported by the physical SF-12 survey score. The differences in the mental SF-12 survey scores were not significant, stating good acceptance of the TFR in both groups. Patients in the present study communicated clearly that regaining partial mobility and reduction of pain are the most important items for achieving satisfaction after TFR. This finding has already been published by other authors $[4,6]$.

This study has several limitations. First, the retrospective design is subject to recall and selection bias. The number of patients is quiet small and statistical analysis is, therefore, difficult. However, owing to the rare indication for this procedure, our series is comparable to studies published so far. Second, the study lacks a true control group, meaning we cannot directly compare our results with other types of implants or biologic reconstructions. Third, the differences between groups regarding age, prior revision surgeries and varying diagnosis make comparison difficult. 


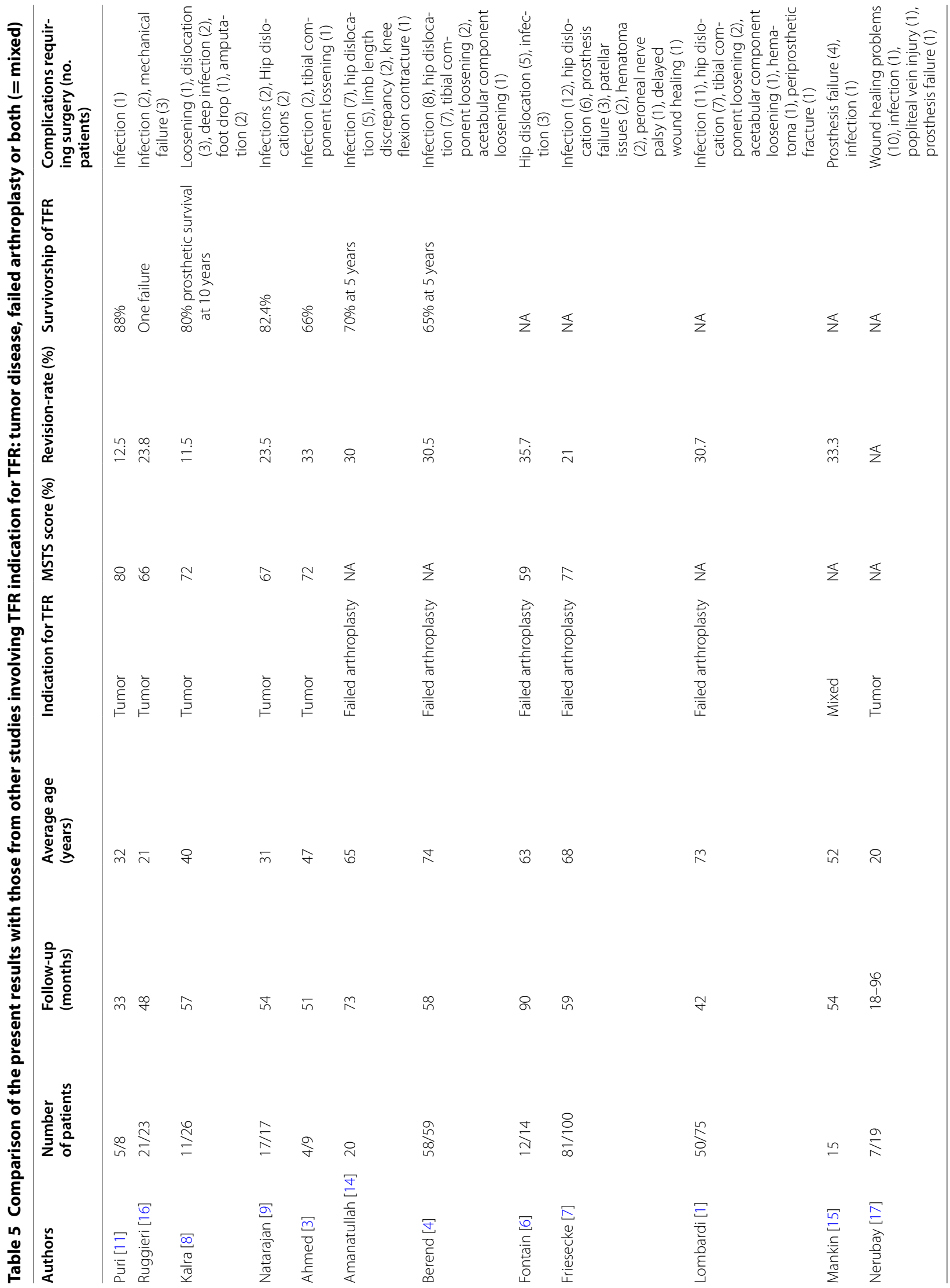




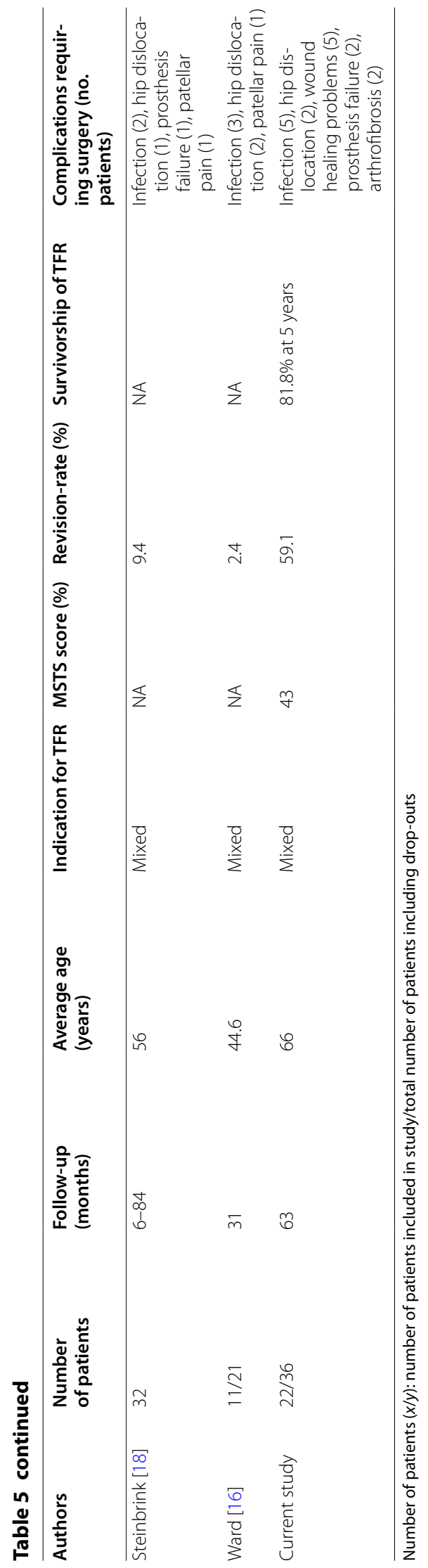




\section{Conclusion}

This retrospective analysis of our series confirmed the high incidence of implant-related complications and failures in TFR for complex oncological and non-oncological lower limb salvage as already outlined by previous studies with different endoprosthetic systems. Infection and soft tissue failure were the most frequent modes of failure. Implant survival of $81.8 \%$ at 5 years was observed. However, only $40.9 \%$ of all TFRs had an uneventful survival at latest follow-up. Clinical outcome seems to depend mainly on the patients' age at reconstruction of bone defect with TFR. Our data suggest that indication for TFR remains a salvage procedure for limb preservation. Therefore, this procedure should only be considered when the alternative is hip disarticulation and the patient should be aware of the potential high complication rates of this massive reconstruction.

\section{Authors' contributions}

AT, IP, NH, HM carried out patient recruitment and clinical investigation. $L G, R v E R, F P, U L, C S$ conceived of the study, and participated in its design and coordination and helped to draft the manuscript. All authors read and approved the final manuscript.

\section{Author details}

${ }^{1}$ Department of Orthopedics and Sports Orthopedics, Technical University of Munich, 81547 Munich, Germany. ${ }^{2}$ Sportmedizin Zürich, Schulthess Klinik, Zurich, Switzerland. ${ }^{3}$ Departmant of Orthopaedic Surgery and Traumatology, University of Schleswig-Holstein, Kiel, Germany.

\section{Acknowledgements}

We thank Prof. Hans Rechl for assisting data extraction from the Clinic Tumor Registry.

\section{Competing interests}

The authors declare that they have no competing interests.

\section{Availability of data and materials}

The datasets supporting the conclusions of this article are included within the article. The raw data can be requested from the corresponding author.

\section{Consent for publication}

Written informed consent was obtained from all patients included in the study.

\section{Ethics approval and consent to participate}

The study was in accordance with the ethical standards of the institutional research committee, the 1964 Helsinki declaration and its later amendments. The Institutional Review Board (IRB) at the Klinikum rechts der Isar approved the study.

\section{Funding}

This study was partially funded by the Wilhelm-Sander Foundation (Fördernummer: 2009.905.2), which is a charitable, non-profit foundation whose purpose is to promote cancer research.

\section{Publisher's Note}

Springer Nature remains neutral with regard to jurisdictional claims in published maps and institutional affiliations.

Received: 6 February 2017 Accepted: 5 January 2018

Published online: 16 January 2018
References

1. Lombardi AV Jr, Berend KR. The shattered femur: radical solution options. J Arthroplasty. 2006;21:107-11.

2. Pennekamp PH, Wirtz DC, Durr HR. Proximal and total femur replacement. Oper Orthop Traumatol. 2012;24:215-26.

3. Ahmed AR. Total femur replacement. Arch Orthop Trauma Surg. 2010;130:171-6.

4. Berend KR, Lombardi AV Jr, Mallory TH, Adams JB, Dodds KL. Total femoral arthroplasty for salvage of end-stage prosthetic disease. Clin Orthop Relat Res. 2004;427:162-70

5. Capanna R, Scoccianti G, Frenos F, Vilardi A, Beltrami G, Campanacci DA. What was the survival of megaprostheses in lower limb reconstructions after tumor resections? Clin Orthop Relat Res. 2015;473:820-30.

6. Fountain JR, Dalby-Ball J, Carroll FA, Stockley I. The use of total femoral arthroplasty as a limb salvage procedure: the Sheffield experience. J Arthroplasty. 2007;22:663-9.

7. Friesecke C, Plutat J, Block A. Revision arthroplasty with use of a total femur prosthesis. J Bone Joint Surg Am. 2005:87:2693-701.

8. Kalra S, Abudu A, Murata H, Grimer RJ, Tillman RM, Carter SR. Total femur replacement: primary procedure for treatment of malignant tumours of the femur. Eur J Surg Oncol. 2010;36:378-83.

9. Natarajan MV, Balasubramanian N, Jayasankar V, Sameer M. Endoprosthetic reconstruction using total femoral custom mega prosthesis in malignant bone tumours. Int Orthop. 2009;33:1359-63.

10. Pala E, Henderson ER, Calabro T, Angelini A, Abati CN, Trovarelli G, Ruggieri P. Survival of current production tumor endoprostheses: complications, functional results, and a comparative statistical analysis. J Surg Oncol. 2013;108:403-8.

11. Puri A, Gulia A, Chan WH. Functional and oncologic outcomes after excision of the total femur in primary bone tumors: results with a low cost total femur prosthesis. Indian J Orthop. 2012:46:470-4.

12. Sevelda F, Schuh R, Hofstaetter JG, Schinhan M, Windhager R, Funovics PT. Total femur replacement after tumor resection: limb salvage usually achieved but complications and failures are common. Clin Orthop Relat Res. 2015;473:2079-87.

13. Abraham AC, Edwards CR, Odegard GM, Donahue TL. Regional and fiber orientation dependent shear properties and anisotropy of bovine meniscus. J Mech Behav Biomed Mater. 2011;4:2024-30.

14. Amanatullah DF, Trousdale RT, Hanssen AD, Lewallen DG, Taunton MJ. Non-oncologic total femoral arthroplasty: retrospective review. J Arthroplasty. 2014;29:2013-5.

15. Mankin HJ, Hornicek FJ, Harris M. Total femur replacement procedures in tumor treatment. Clin Orthop Relat Res. 2005;438:60-4.

16. Ward WG, Dorey F, Eckardt JJ. Total femoral endoprosthetic reconstruction. Clin Orthop Relat Res. 1995;316:195-206.

17. Nerubay J, Katznelson A, Tichler T, Rubinstein Z, Morag B, Bubis JJ. Total femoral replacement. Clin Orthop Relat Res. 1988;229:143-8.

18. Steinbrink K. Procedure in extensive or complete loss of bone substance of the femur following shaft loosening. Orthopade. 1987;16:277-86.

19. Henderson ER, Groundland JS, Pala E, Dennis JA, Wooten R, Cheong D, Windhager R, Kotz RI, Mercuri M, Funovics PT, et al. Failure mode classification for tumor endoprostheses: retrospective review of five institutions and a literature review. J Bone Joint Surg Am. 2011;93:418-29.

20. Ramanathan D, Siqueira MB, Klika AK, Higuera CA, Barsoum WK, Joyce MJ. Current concepts in total femoral replacement. World J Orthop. 2015;6:919-26

21. Mazoochian F, Pietschmann MF, Hocke S, Fottner A, Jansson V. Hip dislocation following THA. Orthopade. 2007;36:935-8.

22. Ruggieri P, Bosco G, Pala E, Errani C, Mercuri M. Local recurrence, survival and function after total femur resection and megaprosthetic reconstruction for bone sarcomas. Clin Orthop Relat Res. 2010;468:2860-6.

23. Ahlmann ER, Menendez LR, Kermani C, Gotha H. Survivorship and clinical outcome of modular endoprosthetic reconstruction for neoplastic disease of the lower limb. J Bone Joint Surg Br. 2006:88:790-5.

24. Biau D, Faure F, Katsahian S, Jeanrot C, Tomeno B, Anract P. Survival of total knee replacement with a megaprosthesis after bone tumor resection. J Bone Joint Surg Am. 2006;88:1285-93.

25. Guo W, Ji T, Yang R, Tang X, Yang Y. Endoprosthetic replacement for primary tumours around the knee: experience from Peking University. J Bone Joint Surg Br. 2008;90:1084-9. 
26. Shehadeh A, Noveau J, Malawer M, Henshaw R. Late complications and survival of endoprosthetic reconstruction after resection of bone tumors. Clin Orthop Relat Res. 2010;468:2885-95.

27. Flint MN, Griffin AM, Bell RS, Ferguson PC, Wunder JS. Aseptic loosening is uncommon with uncemented proximal tibia tumor prostheses. Clin Orthop Relat Res. 2006;450:52-9.

28. Gosheger G, Gebert C, Ahrens H, Streitbuerger A, Winkelmann W, Hardes J. Endoprosthetic reconstruction in 250 patients with sarcoma. Clin Orthop Relat Res. 2006;450:164-71.
29. Healey JH, Morris CD, Athanasian EA, Boland PJ. Compress knee arthroplasty has $80 \% 10$-year survivorship and novel forms of bone failure. Clin Orthop Relat Res. 2013;471:774-83.

30. Gerdesmeyer L, Topfer A, Kircher J, Grundei H, Diehl P. The modular MML revision system in knee revision and tumor arthroplasty. Orthopade. 2006;35:975-81.

\section{Submit your next manuscript to BioMed Central and we will help you at every step:}

- We accept pre-submission inquiries

- Our selector tool helps you to find the most relevant journal

- We provide round the clock customer support

- Convenient online submission

- Thorough peer review

- Inclusion in PubMed and all major indexing services

- Maximum visibility for your research

Submit your manuscript at

www.biomedcentral.com/submit 